\title{
Correspondence
}

\section{The NHS, the private sector and the future}

The times are troubling for the future of the National Health Service (NHS), in the sense of a reasonably comprehensive, effective, equitable and integrated service, free at the point of use, which coordinates the efforts of public health, primary care and hospital-based services for the good of the whole population of the UK.

Before long, all of us will have to take a position, either in favour of the kind of NHS defined above or in favour of an arrangement whereby a variety of private companies compete for market share in the health sector, with the NHS reduced to handing out the money and making some show of monitoring and maintaining standards.

It is time more was said about the moves in various circles, including the Royal College of Psychiatrists, to welcome and foster an increasingly cosy relationship between those responsible for NHS provision and psychiatrists and others working in the private healthcare sector. ${ }^{1}$

The private sector in mental health has a long history, but for many years after 1948 it was confined to a small number of private hospitals with a long pedigree, and the provision of psychotherapy. It grew significantly from the late 1980s onwards as it became clear that the much needed move out of the old system of asylum institutions had involved a miscalculation about how many people would continue to need long-term clinical care in residential settings, supported by staff who have training in the care of people with mental illness.

This calculation may have been partly due to a fantasy, based on ignorance of the realities of severe mental illness, that everyone with these conditions could be assisted to return to completely independent life in the complex place we call the community. The tragedy is that an appropriate and creative range of appropriate accommodation and support was never planned. Be that as it may, there was a miscalculation. Problems were further compounded by the increase in the prison population from the 1990s onwards.

The upshot of this is that there are now excessive numbers of people in private sector residential or hospital care because of severe forms of mental disorder. For example, in the borough where I work there are 83 people in private sector care at an annual cost of over $€ 4$ million (L. King, personal communication, 2011). Of the residents of Greater Manchester currently being treated in medium secure units, around half are in private sector hospitals. This situation has not come about, by and large, because it was found by investigation that this ramshackle arrangement would be the best way to care for this vulnerable group of people. It has arisen through the complacency of governments, the Department of Health, those working in the mental health field including psychiatrists, and health authorities. It has formed the context for the second phase of development of privately run mental health services in the UK. Private providers deserve credit at least for the insight that there was a group of people who would remain in need of care for a long period. Their other insight was to see that this could guarantee a steady and reliable flow of funding from the NHS to form the basis for significant profit-making.

A rational answer to this situation would be to plan a way out of it. This could start with an amalgamation of relevant data on a national basis, including a repeat of the audit of the 'new long stay' carried out on behalf of the College by Lelliott et al and published in 1994. ${ }^{2}$ Unfortunately for the private sector, such an approach would reduce the chaos on which it thrives.

The latest phase of opportunities for the private sector milking the money which most taxpayers think is going to the NHS has been developing for several years and includes venturing into the areas of drug addiction services, assertive outreach teams (in Manchester), counselling services (in Oldham) and intensive community-based care. We could, in fact, use interest from the private sector as an indicator of a need for better local or national planning in any particular area.

There are many examples of excellent and innovative work in the private sector, and at least as many in the NHS. There are also examples of bad and inhumane practice in both sectors. It is not meaningful to compare one flagship private sector provider with the NHS as a whole. The comparison should be between the NHS as a whole and the private sector as a whole, the good, the bad and the ugly.

This year's College International Congress in Brighton featured a session on implementing growth in the independent sector. Could we perhaps get rid of the polite fiction of 'independent' when we mean the private sector? This sector may be independent in many ways, but it is not independent of NHS funding, nor is it independent of the wishes of its directors, shareholders or private equity backers, as, for example, even a brief examination of the recent chains of command and ownership at Castlebeck, the owners of Winterbourne Hospital, and at Southern Cross, will show. ${ }^{3}$

1 Murphy E, Sugarman P. Should NHS mental health services fear the private sector? No. BMJ 2010; 341: c5385.

2 Lelliott P, Wing J, Clifford P. A national audit of new long-stay psychiatric patients. I: Method and description of the cohort. $\mathrm{Br} J$ Psychiatry 1994; 165: 160-9.

3 Brindle D, Curtis P. Care home abuse: ministers move to restore confidence. Guardian 2011; 1 June (http://www.guardian.co.uk/society/ 2011/jun/01/care-home-abuse-ministers-move).

Alistair G. Stewart is a consultant psychiatrist, Royal Oldham Hospital, Oldham, Lancashire, UK, email: alistair.stewart@nhs.net

doi: 10.1192/pb.35.9.354

\section{Alcohol and the over 65s}

The recent report by the Royal College of Psychiatrists' Older Persons' Substance Misuse Working Group ${ }^{1,2}$ advises the lowering of the recommended limit of alcohol consumption for people over 65. The editor of Saga magazine, Emma Soames, reacted to this recommendation by saying that: 'I think people will be infuriated by this. It's described as a public health problem, it's actually a private health matter.' ${ }^{3}$ People over 65 are, overall, very much aware that they need to do things in moderation, which is in fact a good universal advice for the 
young as well as the old. They do not welcome new additions to their ever-expanding list of lifestyle limitations, or being labelled as excessive drinkers by their general practitioner if they choose to drink a pint of beer at night. A holistic approach might well conclude that in many instances an elderly person will be happier and even healthier (in the holistic sense) with a pint, or perhaps even two, than without them.

1 Royal College of Psychiatrists. Psychiatrists call for action to tackle substance misuse in older people (press release). Royal College of Psychiatrists 2011 (http://www.rcpsych.ac.uk/press/pressreleases2011/ ourinvisibleaddicts.aspx).

2 Older Persons' Substance Misuse Working Group. Our Invisible Addicts (College Report CR165). Royal College of Psychiatrists, 2011 (http:// www.rcpsych.ac.uk/files/pdfversion/CR165.pdf).

3 Hughes D. People over 65 should drink less, a report says. BBC News Health 2011; 22 June (http://www.bbc.co.uk/news/health-13863196).

Rafael Euba, consultant psychiatrist and senior lecturer in old age psychiatry, Oxleas NHS Foundation Trust, Memorial Hospital, London, UK, email: Rafael.Euba@oxleas.nhs.uk

doi: $10.1192 /$ pb.35.9.354a

\section{The health status of prisoners is the real challenge}

Exworthy et al are to be commended for their attempt to go beyond the existing interpretation of the doctrine of equivalence of health service delivery in prison healthcare. This has driven improvements in prison healthcare for the past 10 years. However, they fail to identify the next challenge, that of achieving equal health status for prisoners and non-prisoners; this should be the doctrine that informs the strategy for service delivery for the next 10 years. Given the exceptionally high rates of mental and physical ill health in the prison population, not entirely explicable in terms of their sociodemographic profile, this will demand significantly greater investment than is currently the case. Per capita prison healthcare cost $£ 2769$ in 2007-2008, of which only $£ 316$ was for mental healthcare. ${ }^{2}$ However, the advent of outcome-based payments for healthcare and for the management of offenders ${ }^{3}$ allows for the relationship between health gain and criminological outcomes to be explored more rigorously.

The authors cite the UN International Covenant on Economic, Social and Cultural Rights as a guide to future prison health monitoring. This contains nothing to which anyone may object, but it is not specific to this very challenging area of healthcare. Exworthy et al largely neglect the advances in thinking by both the Department of Health ${ }^{4}$ and Her Majesty's Inspectorate of Prisons, ${ }^{5}$ which have led to much improved, relevant markers of activity, performance and outcome in routine review of contract delivery by prison health providers, as well as the role of the Care Quality Commission in assessing prison healthcare. In truth, they look out of step with commissioners and providers of healthcare who are already engaged in the detailed determination of local standards based on a grasp of local needs, for example those of young offenders, older prisoners and women.

Exworthy et al have, as might seem reasonable, a focus on mental health and the important issue of prison transfers. Such problems are relatively rare, although they need quicker resolution than is currently the case. However, they say nothing about primary care, including primary mental healthcare, which is poorly modelled. Nor do they comment on the treatment of drug and alcohol problems, difficulties that compound the management of serious mental illness but where there have been huge improvements in the past 10 years. Most of the prison health budget is devoted to these two areas. Prisoners have often had poor access to primary care and are highly likely to have drug and alcohol problems. The de facto 'polyclinic' nature of the prison environment is different from the external community, but this may be an advantage rather than a disadvantage for rapid healthcare delivery. Within a short period of time a prisoner can have a health check and be stable enough to reflect and plan for the future. For this to work, practitioners, including senior psychiatrists, will be required to operate in an integrated and multifaceted system of holistic care delivery where acute mental illness, for all its headline grabbing potential, is not the main issue.

\section{Declaration of interest}

A.B. and F.A. are joint clinical directors in offender care, Central and North West London NHS Foundation Trust, and work clinically and have clinical director responsibility for a range of health services delivered to three London prisons.

1 Exworthy T, Wilson S, Forrester A. Beyond equivalence: prisoners' right to health. Psychiatrist 2011; 35: 201-2.

2 Brooker C, Duggan S, Fox C, Mills A, Parsonage M. Short-Changed: Spending on Prison Mental Healthcare. Sainsbury Centre for Mental Health, 2008.

3 Ministry of Justice. Breaking the Cycle: Effective Punishment, Rehabilitation and Sentencing of Offenders. TSO (The Stationery Office), 2010.

4 Department of Health, National Offender Management Service, Her Majesty's Prison Service. Guidance Notes: Prison Health Performance and Quality Indicators. Department of Health, 2008.

5 Her Majesty's Inspectorate of Prisons. Expectations: Criteria for Assessing the Conditions in Prison and the Treatment of Prisoners. HMIP, 2008.

Annie Bartlett is reader in forensic psychiatry, St George's, University of London, email: abartlet@sgul.ac.uk; Farrukh Alam is a consultant psychiatrist, Central and North West London NHS Foundation Trust.

doi: $10.1192 / p b .35 .9 .355$

\section{Personality disordered offenders - complex patients requiring more expertise}

The ongoing debate on the management of personality disordered offenders has been further stimulated by the recently concluded Department of Health and National Offender Management Service joint consultation paper on the proposed personality disorder care pathway. ${ }^{1}$

The Labour government's flagship Dangerous and Severe Personality Disorder pilot programme is being scaled down at present to make way for national personality disorder services. ${ }^{2}$ Approaching the conclusion of the Programme, clinicians are still looking at the most effective treatment regimes and politicians are still striving to ensure that the public protection element of treatment is not overlooked. Both parties are labouring to find the most effective way of managing this group of offenders who are considered to be 'difficult to treat', 'high risk' and 'carrying a high morbidity and stigma'.

Thus, we welcome and value the suggestion of early identification and provisions for a suitable care pathway for personality disordered offenders. ${ }^{1}$ A standardised early identification system with clear pathways of treatment is likely 